\title{
Mobilization of CD34/CD133 positive stem cells in surgical patients with complicated intra abdominal infection.
}

\author{
A Cotoia, L Mirabella, S Altamura, R Villani, L Tullo, G Cinnella. \\ Department of Intensive Care, University of Foggia, Italy
}

\section{Introduction}

Sepsis is a frequent cause of mortality in patients undergoing major abdominal surgery (AS) with complicated intra-abdominal infection (IAC). We currently lack of informations regarding the endothelial stem cells surgical patients.

\section{Objectives}

The aim of the study is to evaluate the time course level of circulating CD34/133 positive endothelial stem cells in AS-IAC patients.

\section{Methods}

Consecutive AS patients were enrolled at University Hospital of Foggia. Blood samples were collected at baseline and 1-3-7-10 days postoperatively to perform CD34/133 cells quantitative analysis. The outcome was also recorded. The data are presented as median [IQR].

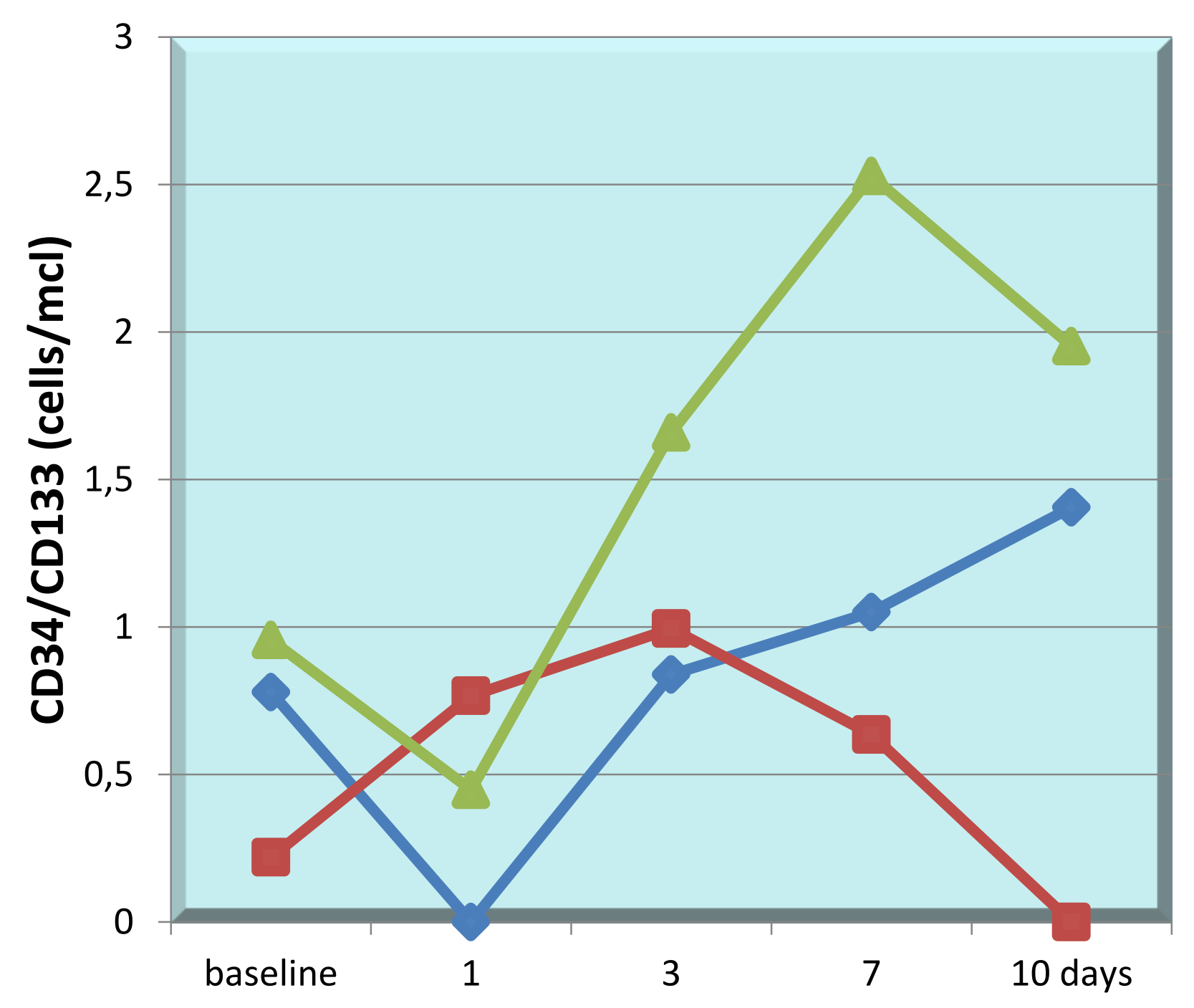

\section{Results}

Of 46 AS patients, 28 AS patients developed IAC and septic shock. 16 of 28 AS-IAC septic shock patients died within 15 days postoperatively. CD34/133 cells number progressively increased in AS patients at 7 vs 1 postoperative day $(1,05$ cells $/ \mathrm{mcl}[0-3,1]$ vs 0 cells $/ \mathrm{mcl}[0-1,2]$, respectively; NS) and in survivors AS-IAC septic shock patients (7 vs 1 postoperative day: 2,5 cells $/ \mathrm{mcl}[0-6,8]$ vs $0,4$ cells $/ \mathrm{mcl}[0-1,5] ; p=0,04)$. Differently, in non survivors AS-IAC septic shock patients CD34/133 increased at 3 days vs baseline $(0,9 \mathrm{cells} / \mathrm{mcl}$ [0$2,4]$ vs 0,2 cells $/ \mathrm{mcl}[0-2,3]$ and progressively decreased at 10 days ( 0 cells/mcl $[0-1,2]$ ).

\section{Conclusions}

The presented preliminary findings indicate a increased level of the circulating CD34/CD133 stem cells in the blood of AS patients likely due to an adaptive response to surgical stress. Moreover it appears that AS-IAC septic shock patients mobilizing CD34/133 stem cells exhibit a better outcome. The preliminary data encourage the continuation of the research project on a larger sample size of patients to better understand if and how CD34 stem cells are involved in the surgical patients with septic shock.

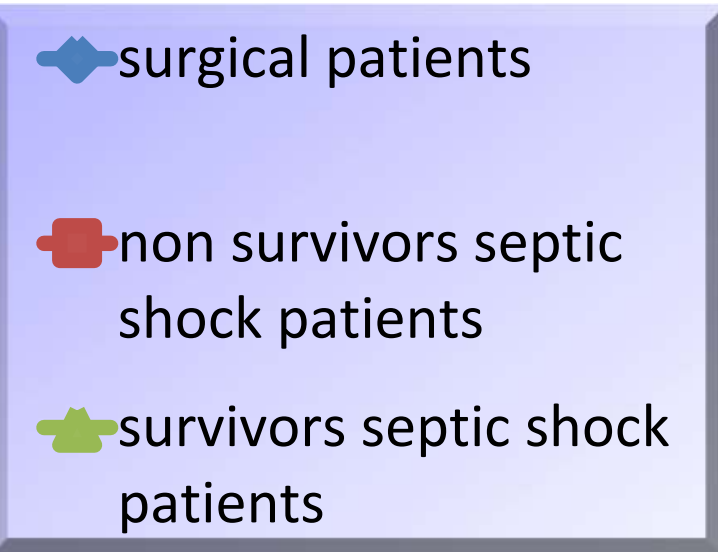
undergoing major abdominal surgery. 